\title{
Accelerate Implementation of the WHO Global Code of Practice on International Recruitment of Health Personnel: Experiences From the South East Asia Region
}

\author{
Comment on "Relevance and Effectiveness of the WHO Global Code Practice on the \\ International Recruitment of Health Personnel - Ethical and Systems Perspectives"
}

Viroj Tangcharoensathien ${ }^{1^{*}}$, Phyllida Travis ${ }^{2}$

\section{Abstract}

Strengthening the health workforce and universal health coverage (UHC) are among key targets in the heathrelated Sustainable Development Goals (SDGs) to be committed by the United Nations (UN) Member States in September 2015. The health workforce, the backbone of health systems, contributes to functioning delivery systems. Equitable distribution of functioning services is indispensable to achieve one of the UHC goals of equitable access. This commentary argues the World Health Organization (WHO) Global Code of Practice on International Recruitment of Health Personnel is relevant to the countries in the South East Asia Region (SEAR) as there is a significant outflow of health workers from several countries and a significant inflow in a few, increased demand for health workforce in high- and middle-income countries, and slow progress in addressing the "push factors." Awareness and implementation of the Code in the first report in 2012 was low but significantly improved in the second report in 2015. An inter-country workshop in 2015 convened by WHO SEAR to review progress in implementation of the Code was an opportunity for countries to share lessons on policy implementation, on retention of health workers, scaling up health professional education and managing in and out migration. The meeting noted that capturing outmigration of health personnel, which is notoriously difficult for source countries, is possible where there is an active recruitment management through government to government ( $G$ to $G$ ) contracts or licensing the recruiters and mandatory reporting requirement by them. According to the 2015 second report on the Code, the size and profile of outflow health workers from SEAR source countries is being captured and now also increasingly being shared by destination country professional councils. This is critical information to foster policy action and implementation of the Code in the Region. Keywords: Implementing WHO Global Code, International Migration of Health Personnel, South East Asia Region (SEAR), Capturing Data on Out-migration of Health Workers, Source and Destination Countries Copyright: $\odot 2016$ by Kerman University of Medical Sciences

Citation: Tangcharoensathien V, Travis P. Accelerate implementation of the WHO Global Code of Practice on International Recruitment of Health Personnel: experiences from the South East Asia Region: Comment on "Relevance and effectiveness of the WHO Global Code Practice on the International Recruitment of Health Personnel - ethical and systems perspectives." Int JHealth PolicyManag. 2016;5(1):43-46. doi:10.15171/ijhpm.2015.161
Article History:

Received: 15 July 2015 Accepted: 29 August 2015 ePublished: 30 August 2015

View Video Summary

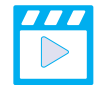

*Correspondence to:

Viroj Tangcharoensathien Email: viroj@ihpp.thaigov.net

\section{Background}

Universal health coverage (UHC) goals are to ensure equitable access to healthcare by all citizens without suffering financial hardship. A well functioning delivery system with adequate numbers of competent health workers contributes to equitable access to services. Strengthening the health workforce requires multipronged strategies including investment in education and training of students recruited from underserved or ethnic communities, reform of curricula and training materials which better reflect local health needs, creating a safe work environment, and managing financial and nonfinancial incentives to attract and retain them in the communities where they are needed most. ${ }^{1}$ The health workforce is argued to be the backbone of health systems and indispensable to achieve UHC. ${ }^{2}$

Health workers are sensitive to three factors: remuneration, working conditions, and career prospects. ${ }^{3}$ Disparities in these factors both within and across countries create powerful market forces for internal and international migration, often negatively impacting the provision of health services in underserved areas. Management of domestic and international migration of health personnel requires an understanding of these market forces, and where interventions can be introduced effectively.

Shortages and maldistribution of health personnel have been constant challenges in many countries despite the 2008 Kampala commitment, ${ }^{4}$ Bangkok Statement ${ }^{5}$ and reiterated by the Recife Political Declaration. ${ }^{6}$ Investment in the training of health workforce remains low, with large gaps between demand and supply; weak planning and lack of inter-sectoral coordination. ${ }^{7}$ Six out of 57 countries facing critical shortages of health workers as identified by the 2006 World Health Report $^{8}$ were in the World Health Organization (WHO) South-East Asia Region (SEAR). By 2014, 6 countries in SEAR 
still had critical shortages of health workforce'; Myanmar has 1.61 doctors, nurses and midwives per 1000 population, below the global benchmark of 2.28 per 1000 population. ${ }^{8}$ Health workforce population ratio in Indonesia was 1.58 , Bhutan 1.24, Timor Leste 1.18, Nepal 0.67 and Bangladesh 0.58 . However, recently Indonesia had increased its production and is no longer classified as having a critical shortage: in 2015 their health workforce density was 3.22 per 1000 population. Maldistribution of the health workforce remains common in most countries in the Region, even among 'non-shortage' countries. Health workers are concentrated more in the urban hospital sector, hampering access to health services by the poor rural population.

In response to Brugha and Crowe's editorial, ${ }^{10}$ this commentary argues that the Code is still relevant to SEAR, but awareness could be improved and implementation is just beginning. It reviews implementation of the Code in a few countries, each with a distinct health workforce context, and draws some lessons on how to accelerate implementation of the Code in SEAR.

The Code: Relevant to the Region Though Uneven Implementation

As the commitment towards the Millennium Development Goals (MDGs) draws to a close in 2015, the global community will commit to the Sustainable Development Goals (SDGs) at the United Nations (UN) General Assembly in September 2015.

In the SDG goal 3 for health, target 3.8 commits by 2030 to "achieve UHC, including financial risk protection, access to quality essential healthcare services and access to safe, effective, quality and affordable essential medicines and vaccines for all." Also Target 3.c commits to "Substantially increase health financing and the recruitment, development, training and retention of the health workforce in developing countries, especially in least developed countries and small island developing States."

There have been significant outflows of health workers from SEAR countries for some time. The bulk of the immigrant health workforce in the Organization for Economic Cooperation and Development (OECD) circa 1990 were Indianborn doctors - approximately 56000 , or $15 \%$ of the total stock of immigrant health workers in OECD countries. ${ }^{11}$ When measured by expatriation rate (ratio of doctors practicing outside country of origin to the total doctors in the country of origin), Sri Lanka has the highest expatriate rate to OECD countries: $30.8 \%$ of the total doctors practicing in Sri Lanka. In a small population country such as Timor Leste, small absolute numbers may represent a large proportion of the total available stock of health workers: the 35 doctors from Timor Leste practicing in OECD account for $30.7 \%$ of the total physician stock in Timor.

Both pull and push factors influence these outflows. Demand for health workers due to the demographic and epidemiologic transition in high- and middle-income countries is a strong pressure on continued international migration. The migration of high skilled health workers is also triggered by the slow progress in resolving the "push factors" in source countries such as low pay, lack of career paths and poor working conditions.
Looking forward, these factors are highly relevant to achieving the SDG target for UHC in the Region. Countries such as Bhutan, Maldives, Sri Lanka and Thailand, and Indonesia have already overall achieved high population coverage with essential health services, though inequity in term of distributions of health workers and delivery infrastructure such as primary healthcare centers and hospitals still persist, between urban and rural areas, and rich and poor. Achieving UHC in BRICS (Brazil, Russia, India, China, and South Africa) countries (including India) is a global breakthrough, as this group constitutes $42 \%$ of the world population and approximately $25 \%$ of the gross world product. There are several health system reforms designed to extend, deepen or improve health service coverage for their populations while working on ways to increase financial protection. ${ }^{12}$ Despite strong political commitment, achieving UHC in SEAR by 2030 will be challenging especially if the health workforce, a critical success factor for a functioning health delivery system, is not fully addressed.

Against this background, the Code is an appropriate instrument for strengthening the health workforce in lowand middle-income countries. Not only does it underlie the principles of international solidarity, it promote fair employment practices in destination countries, recognizes the rights of migrant health workers; and it supports scaling up training and retention of health workforce in a comprehensive manner.

Despite the relevance of the Code, implementation in SEAR was initially quite slow. Only 3 of 11 Member States in the Region nominated a national focal point for the Code in the first round of reporting in 2012. And only 2 countries actually reported they were taking steps to implement the Code and share information on matters pertaining to health workers recruitment and migration as well as the Code itself. ${ }^{13}$

\section{Recent Implementation of the Code}

In July 2015, an inter-country workshop was convened by WHO SEAR to review progress of the implementation of the Code and support the 2nd round of reporting in 2015 as requested by the World Health Assembly (WHA) Decision. ${ }^{14}$ An improving trend was observed in that 6 out of 11 Member States had nominated a focal point while five submitted the second round report. Variation in progress with actual implementation was noted.

A number of challenges were identified in the workshop, as well as progress on specific elements of the Code. Countries with small populations such as Maldives, Timor Leste, and Bhutan have limited capacities, and no economy of scale to produce their own physicians in their national universities, though they do produce nursing and other related professionals locally. This has led to bilateral agreements with neighboring countries to train doctors. However, these do not necessarily mean doctors return home to work: in the Maldives, despite a government bonding requirement following overseas training, some do not adhere to this requirement for which tough measures will be introduced. Also more than $90 \%$ of physicians in atolls today are expatriates, with high turn over rates. Maldives has fully observed one important aspect of the Code: expatriate doctors have similar rights and privilege to domestic physicians. 
Thailand and Indonesia are self-reliant on the training of health workforce and post-graduate specialist training. Indonesia by contrast has a surplus of nurse and midwife personnel (in term of absolute number but may have shortage in some areas due to maldistribution). This triggered government policies to enter into formal agreements with a few Middle East countries, and Japan related to recruitment of their nurses. This has been mostly through a government to government ( $G$ to $G$ ) mechanism, though private recruitment is not uncommon. The $G$ to $G$ mechanism supports predeparture briefings, ensures fair employment practices, develops information systems on number and profiles of migrated health personnel and facilitates circular migration. Indonesia and Thailand have translated the Code into local languages (since the first reporting in 2013) and it has been widely circulated to professional associations and councils and relevant health professional training faculties. This increases awareness of the Code. Active implementation in particular to tackle rural retention ${ }^{15}$ and transforming and scaling health professional education was reported.

Thailand is at present neither a major destination of migrant health personnel nor a source country - despite the Association of Southeast Asian Nations (ASEAN) mutual recognition agreement for health workers. However, as one of the major medical hubs ${ }^{16}$ in Asia, domestic migration of specialists from public to private practice and cascade migration from rural to urban are major policy concerns. It may accentuate the negative impact on maldistribution and access to specialists among Thai citizens.

The WHO SEAR has made a number of significant political commitments to health workforce strengthening in the last few years. There is a regional strategy on strengthening health workforce education and training 2014-2019, and a regional Resolution on the same in $2014 .{ }^{17}$ Importantly, the Resolution urges Member States to implement WHO global policy recommendations on increasing access to health workers in remote and rural areas, as well as addressing education and training. This is in line with the comprehensive content of the Code. The decade for health workforce strengthening in SEAR (2015-2024) which was agreed at the end of 2014 is another landmark to stimulate action on health workforce strengthening. Member States have committed to report on progress on health workforce development to the Regional Committee for South-East Asia every 2 years starting 2016 for the next decade.

\section{Lessons and the Way Forwards}

Reliable information on migration remains a challenge. Capturing information of in-migration to the destination country is feasible, as professional licensing is mandatory required by relevant professional councils in destination countries. However, data capture of out-migration from the source countries is not feasible unless, as demonstrated by Indonesia, there is a systematic $G$ to $G$ arrangement, or licensing of private recruiters and a requirement of regular report of their recruitments to the national health authority. Opportunities are arising in SEAR source countries to obtain and maximize use of information on the size and profiles of their out-migrating health workers which is being captured and shared by health professional councils in destination countries, according to the 2015 report of the Code. This information is critical to foster policy action and active implementation of the Code in the Region. Data sharing of in and out migration of health workers is one of the normative functions of the Code, supporting international solidarity. Participants at the July 2015 inter-country workshop, after reviewing implementation of the Code, observed that periodic Code reporting should become a useful exercise for Member States, not just an end in itself. They recommended that the Regional Office proactively involve all Member States, whether a focal point to the Code is nominated or not, to review progress in health workforce strengthening in a comprehensive manner, not only focusing on international migration, before the next Code reporting requirement in mid 2018. This will help to create awareness of the Code and accelerate the health workforce agenda in Member States.

Ethical issues

Not applicable.

Competing interests

Authors declare that they have no competing interests.

Authors' contributions

VT and PT jointly conceptualized, wrote the first draft manuscript, revised according to peer review and agreed on the final draft.

\section{Authors' affiliations}

${ }^{1}$ International Health Policy Program, Ministry of Public Health, Nonthaburi, Thailand. ${ }^{2}$ WHO South East Asia Region Office, New Delhi, India.

\section{References}

1. World Health Organization (WHO). Increasing access to health workers in remote and rural areas through improved retention. http://www.who.int/hrh/retention/home/en/index.html. Accessed August 7, 2015. Published 2010.

2. Tangcharoensathien V, Mills A, Palu T. Accelerating health equity: the key role of universal health coverage in the sustainable development goals. BMC Med. 2015;13:101. doi:10.1186/ s12916-015-0342-3

3. World Health Organization (WHO). WHO Health Workforce 2030: Towards a Global Strategy on Human Resources for Health. Geneva: WHO; 2015.

4. World Health Organization (WHO), Global Health Workforce Alliance. The Kampala declaration and agenda for global action, 2008. http://www.who.int/workforcealliance/Kampala\%20 Declaration\%20and\%20Agenda\%20web\%20file.\%20FINAL. pdf. Accessed August 24, 2015.

5. Prince Mahidol Award Conference 2011, From Kampala to Bangkok: Reviewing Progress, Renewing Commitments. The Outcome Statement of the Second Global Forum on Human Resources for Health, Bangkok, 27-29 January 2011. http://www. who.int/entity/workforcealliance/forum/2011/Outcomestatement. pdf?ua=1. Accessed August 2015, 2015.

6. WHO Recife Political Declaration on Human Resources for Health, Human Resources For Health: foundation for Universal Health Coverage and the post-2015 development agenda. http://www.who.int/workforcealliance/forum/2013/recife declaration_13nov.pdf. Accessed August 25, 2015.

7. Global Health Workforce Alliance. The 3rd Global Forum on Human Resources for Health The Recife Political Declaration on Human Resources for Health: renewed commitments towards universal health coverage. http://www.who.int/workforcealliance/ 
forum/2013/recife_declaration_17nov.pdf?ua=1. Accessed March 22, 2015.

8. World Health Organization (WHO). The World Health Report 2006: Working Together for Health. Geneva: WHO; 2006

9. World Health Organization (WHO). World Health Statistics 2014. Geneva. Geneva: WHO; 2014

10. Brugha R, Crowe $S$. Relevance and effectiveness of the WHO Global Code Practice on the International Recruitment of Health Personnel - ethical and systems Perspectives. Int $\mathrm{J}$ Health Policy Manag. 2015;4(6):333-336. doi:10.15171/ijhpm.2015.103

11. Economic Co-operation and Development (OECD). International Migration Outlook 2007. Paris: OECD Publishing; 2007.

12. Marten R, Mclntyre D, Travassos C, Shishkin S, Longde W, Reddy S. An assessment of progress towards universal health coverage in Brazil, Russia, India, China, and South Africa (BRICS). Lancet. 2014;384(9960):2164-2171. doi:10.1016/ S0140-6736(14)60075-1

13. Siyam A, Zurn $P, R ø O C$, et al. Monitoring the implementation of the WHO Global Code of Practice on the International Recruitment of Health Personnel. Bull World Health Organ. 2013;91:816-823

14. World Health Organization (WHO). WHO Global Code of Practice on the International Recruitment of Health Personnel. World Health Assembly Decision WHA68(11). http://apps. who.int/gb/ebwha/pdf_files/WHA68/A68_DIV3-en.pdf. Access August 25, 2015.

15. Putthasri W, Suphanchaimat R, Topothai $T$, Wisaijohn $T$, Thammatacharee N, Tangcharoensathien V. Thailand special recruitment track of medical students: a series of annual crosssectional surveys on the new graduates between 2010 and 2012. Hum Resour Health. 2013;11:47. doi:10.1186/1478-4491-11-47

16. NaRanong A, NaRanong $V$. The effects of medical tourism: Thailand's experience. Bull World Health Organ. 2011;89:336344. doi:10.2471/BLT.09.072249

17. World Health Organization (WHO) South East Asia Region (SEAR). Strengthening Health Workforce Education and Training in the Region. Resolution of the WHO Regional Committee for South East Asia, SEA/RC67/R6. New Delhi: WHO SEARO; 2014. 